\title{
Driver's Behavioral Pattern in Driver Assistance System
}

\author{
Doori Jo*, Donghee Shin**
}

\section{Abstract}

This paper analyzes the recognition of driver's behavior in lane change using context-free grammar. In contrast to conventional pattern recognition techniques, context-free grammars are capable of describing features effectively that are not easily represented by finite symbols. Instead of coordinate data processing that should handle features in multiple concurrent events respectively, effective syntactic analysis was applied for patterning of symbolic sequence. The findings proposed the effective and intuitive method for drivers and researchers in driving safety field. Probabilistic parsing for the improving this research will be the future work to achieve a robust recognition.

Keywords : driver assistive system, driver behavioral pattern, context-free grammar, syntactic model, pattern recognition

\section{운전자 사용자경험기반의 인지향상 시스템 연구}

\author{
조두리*, 신동희**
}

\section{요 약}

본 논문은 문맥-자유 문법 (context-free grammar)를 이용하여, 차선변경 상황에서의 운전자의 행동 패턴 인식을 하는 방법을 제안하는 것을 목표로 한다. 문맥-자유-문법은 기존 패턴인식 방식과는 대조적 으로 유한적 기호로는 쉽게 표현될 수 없는 특징들을 비교적 손쉽게 표현할 수 있다. 이 방식을 적용하 여, 동시에 여러 특징을 각각 고려해야 하는 좌표기반 데이터 처리 대신 심볼 시퀀스 방식 (symbolic sequence)을 패턴화하기 위해 구문론적 방식을 적용한다. 이 방법은 운전자와 안전 운전 분야 연구자들 에게 효율적이고 보다 직관적인 방법으로 보다 더 효과적인 수행에 도움이 된다. 본 연구의 향후과제로 보다 안정적인 인식률을 획득하기 위해 확률적 구문분석 방법을 적용할 계획이다.

키워드 : 운전자 사용자 경험, 운전자 운전 패턴, 운전자 인지기반, 문맥자유언어

\section{Introduction}

※ 교신저자(Corresponding Author): Donghee Shin 접수일:2014년 08월 18일, 수정일:2014년 10월 15일 완료일:2014년 10월 21일

*성균관대 인터랙션 연구원, jdl6427@gmail.com

** 성균관대학교 인터랙션사이언스학과 교수

Tel: +82-2-880-7008, Fax: +82-2-880-7010

email: dshin@skku.edu

घ This work was supported by the National Research Foundation of Korea Grant funded by the Korean Government (Social Science Korea; NRF-2011-330-B00225).

\subsection{Recognition of Driver's Behavioral Pattern for Driver Assistance System \\ Modeling and recognizing human driving} behavior have been of great interest to researchers from diverse disciplines such as psychology, physiology, and ergonomics. Notable progress has been made from the numerous specific studies on the various aspects of human physiology and psychology by capturing biological data. Driver model research has been made from the perspective of vehicle dynamics application and human 
factors. Output parameters of driver models are usually steering wheel angle/torque, acceleration or brake pedal position/pressure, and the gear shift position. It has been commonly known that driving a car is a complex and dynamic task requiring drivers not only to make accurate perceptions and cognitions about information pertaining to the driver's own driving skill, driver state, vehicle performance, and traffic, but also to process all these information at a high rate of speed. Modeling human driving behavior and recognizing driver characteristics are necessary to relieve the driver's workload and improve the reliability and amenity of active vehicle safety systems, for example, collision detection and avoidance systems, and road departure warning systems. These active safety systems, however, were designed only based on an average of driver performance in a limited way and rarely takes the individual driver's characteristics into consideration.

On average, 600 accidents and 23 fatalities on Korea roads everyday from 1980s [1] and with more than 33,000 fatalities on US roads each year [2]. Since the most of the traffic accidents caused by driver's negligence and inattention, Driver Assistance System which make use of a holistic and comprehensive awareness of the surround, vehicle, and driver is needed in order to predict and mitigate dangerous or uncomfortable circumstances. Although advances of vision sensor technology have been supporting the development of Driver Assistance System, it is not easy to exactly know what is the driver's intention.

Researchers of driving safety field have long been interested in understanding drivers' cognitions as they play a important role in driving [3]. Through recognition and understanding of driving behavior, it is possible to characterize the driver's behavior under the specific driving situation. For example, automotive researchers found that there were between $65-92 \%$ probabilities of glancing at a mirror prior to a left or right lane change [4]. Understanding the correct driver's behavior would be extremely beneficial for Driver Assistance System by improving system performance or early priming of corrective behaviors, e.g. suppress lane departure warnings and engage a lane change assistant when a driver wants to make a lane change [5].

As aforementioned, understanding of driver's cognition and behavior is critical for improving Driver Assistance System as this improved system can support driver's safety. For example, since drivers only use their blinkers half the time before a lane change [6], they could be engaged automatically to notify surrounding vehicles of the impending maneuver. Blind spot systems might be better accepted if warnings were only presented when needed (driver is unaware of blind spot vehicle). Adaptive Cruise Control function assisted overtakes could be made more natural by accelerating into the lane change rather than waiting to clear a lead vehicle. In risky situations, the vehicle could warn the driver of impending danger or could even take over control of the vehicle to completely avoid collision.

\section{Literature Review}

\subsection{Driver behavior research for Driver Assistance System}

In their research, Oliver and Pentland [7] distinguish between 7 distinct driving maneuvers, each decomposed into a sequence of actions using (coupled) Hidden Markov model (HMM). Recently, Berndt et al. [8] used HMMs for continuous prediction of lane changes and turns. The first 3 HMM action states were used for early detection. Other researchers have focused on a single 
maneuver, such as lane change, and adopted traditional machine learning and pattern recognition techniques. An HMM utilizing vehicle dynamics measurements was able to distinguish between lane keeping and lane changes [9]. Salvucci et al. [10] incorporated vehicle dynamics, lane, and ACC radar information into a driver cognitive model of lane change. Researchers in San Diego, California have used the relevance vector machine to predict driver intentions to change lanes [10], [11], brake [10], and turn [12]. These studies developed a holistic understanding of the driving situation by utilizing a number of sensors. They relied heavily on the patterns of visual search (eye and head motion) that precede maneuvers for predictability.

While it has been shown that a driver's lane change intent can be predicted, such a system has not been implemented and deployed in a moving vehicle. It is currently unknown how the performance of the above intent prediction schemes will translate from the laboratory into a real vehicle and whether intent prediction is ready for the next generation Advanced Driver Assistance System (ADAS).

\subsection{Recognition of Driver behaviors}

There has been substantial amount of research on structural model-based event recognition. $\mathrm{Vu}$ et al. [14] proposed the activity recognition problem as a constraint satisfaction problem. Ghanem et al. [15] proposed the use of high-level Petri-Nets for representing and recognizing events. Ivanov and Bobick [16] described a method for modeling and recognizing activities using stochastic context-free grammars (CFG) and stochastic parsing. The parser corrected substitution and insertion errors and handled concurrent tracks from separate objects using insertion error correction. The consistency between interacting objects was enforced by simple spatial-temporal conditions. Stochastic CFG was also used by Moore and Essa [17] to recognize events involving multiple entities. Stochastic parsing was applied to each separable group (independent interactions) in blackjack games. Insertion, substitution, and deletion errors were handled by ignoring or hypothesizing terminal symbols and considering multiple hypothesized parsing paths.

To characterize multi-tasked activities, we came up with models that can identify the regularities associated with complex tasks while also tolerating the dynamics associated with multiple participants and interactions scattered through time. Grammar is a mechanism that uses a system of rules to generate semantically meaningful expressions. Its ability to accommodate variation makes it a compelling choice for modeling complex activities, particularly those that are rule-based, event-driven.

Grammar is not susceptible to some of the limitations of probabilistic finite state machine representations, like the HMMs. Finite state machines are appropriate for modeling a single hypothesis or a series of them in parallel. However, as variation becomes more pronounced, it becomes exceedingly difficult to collapse additional hypotheses into a single finite state model. In contrast, the generative process associated with grammar is non-deterministic, allowing the derivation of a much longer and elaborate sequence of events [18]. Grammar allows us to use a single, compact representation for well-understood interactive events that also accommodates the natural generalizations that occur during their performance.

\section{Research Objective \& Methods}


Researchers in numerous previous studies have attempted to predict and understand driver's behavior from behavior pattern of driver through pattern recognition [10-12]. Recognition of short-term events such as voice recognition has been studied extensively using statistical pattern recognition techniques, primarily Hidden Markov Models. However, it is difficult to apply the same approach to the problem of recognizing events that span extended periods of time with complex structure involving multiple interacting objects [13]. A major difficulty is that for complex activities, very little training data is available compared to the huge dimensionality of its feature space. Also, semantically equivalent activities may often have feature values that are quite far apart. Such complex events can be more suitably represented by an explicit model of the structure in the pattern using domain knowledge. In this paper, eye tracking data of driver in lane change in natural driving was collected then a syntactic model of the event structure based on stochastic context-free grammar was applied.

\subsection{Experiment Design}

This experiment was composed of three stages: (1) setting the eye-tracking system for every participant, (2) setting ROI (Region of Interest), and (3) collecting data from participants in lane change. First of all, for the on-road pattern recognition, eye-tracking system was built in a car. Then, 3 steps camera calibration (Step 1: Calibrating between eye-tracking cameras, Step 2: calibrating between a subject and calibrated Step 1, Step 3: Calibrating between a scene camera and calibrated step 2) were conducted by researcher to every participants. It is not only for tracking subject's gaze movement but also tracking where is subject looking at.

Then, symbolic ROIs(Region of interest) were set by simple experiment. After the calibration stage, each of participants stared assigned objects(A front of view, Left side mirror, Rear mirror, Right side mirror). This stage conducted for the estimation of the allowable region when the subject stare the assigned objects. The ROIs is described in the (figure 1). from this experiment. Then, finally driver's eye-tracking data and recordings of scenes was collected in lane change situation. These data were collected for making grammar of driver's lange change behavior. After data preprocessing, grammar was made.

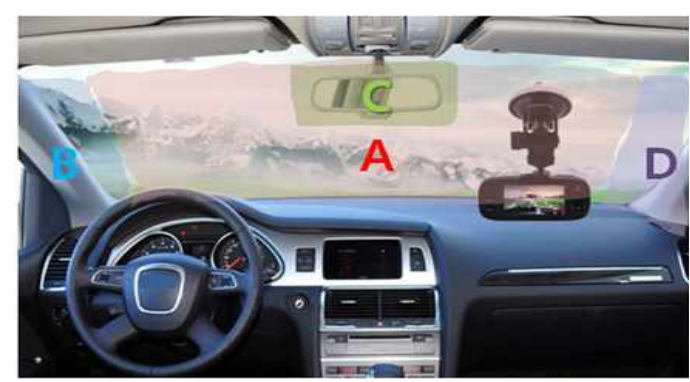

(Figure 1) Symbolic ROIs (Region of Interest)

\subsection{Apparatus}

All participants had their eye movements tracked using a SMART EYE PRO eye tracker (developed by SMART EYE Cop., Sweden). Three cameras with 2 IR flashes was attached on top of the dash board and recorded what participants saw from their own viewpoint and the eye movements of participants were sampled, from the both eyes, at a rate of $60 \mathrm{~Hz}$. The temporal resolution of the eye movement equipment was $25 \mathrm{~Hz}$, and the spatial accuracy was 1 . For the purposes of analysis, the tool MAPPS which can deal with professionally eye-tracking data from SMART EYE PRO was utilized. 


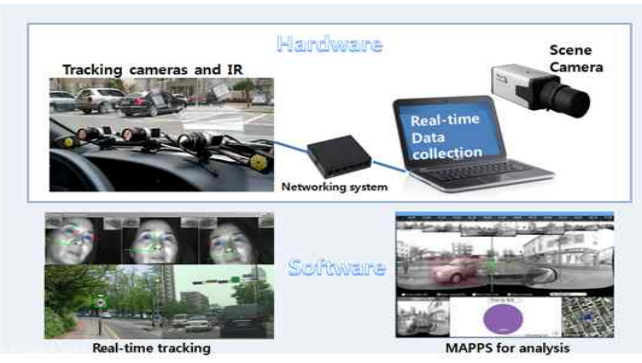

(Figure 2) Eye-tracking system SMART EYE PRO and Analyzing tool MAPPS

\subsection{Data Acquisition}

Using the analyzing tool MAPPS, it is possible to set the ROI on the scene camera and transforming the output of tracked as two dimensional data (estimated gaze direction vector position based on fixed tracking camera) into two dimensional intersection with gaze direction and scene. From this, coordinated data changed into symbolic ROI data.

SMART EYE PRO Data frame is $60 \mathrm{~Hz}$, it means that 60 data per second. Considering the spending time of lane change is over 7 sec on average [9], data quantity is unnecessarily big. MAPPS can filter out inaccurate data and select data have estimated intersection with the scene. Data preprocessing was possible through analysing tool and brief, clear data for making grammar was obtained.

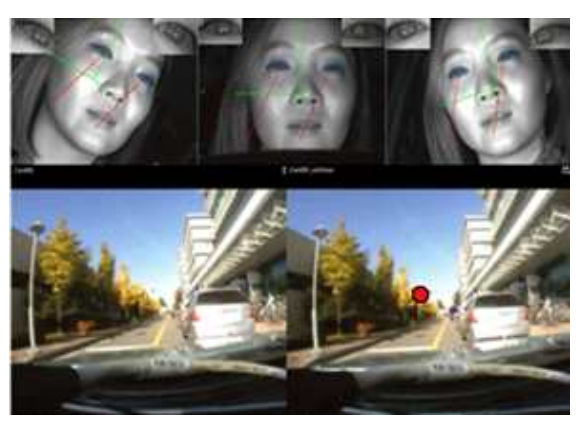

\begin{tabular}{|c|c|c|c|}
\hline$X$ & $Y$ & $Z$ & \\
-0.046139661 & 0.039235996 & 0.703583219 & \\
-0.04615059 & 0.03919538 & 0.70387405 & \\
-0.04617924 & 0.039357452 & 0.705268426 & \\
-0.046114745 & 0.03915601 & 0.704636279 & $A$ \\
\hline-0.046067237 & 0.039331794 & 0.704614173 & $A$ \\
\hline-0.046053777 & 0.039119041 & 0.704131136 & $A$ \\
\hline-0.04607769 & 0.039319184 & 0.704506078 \\
\hline-0.046069419 & 0.039286258 & 0.704170675 & B \\
\hline-0.046073401 & 0.039197409 & 0.703798944 & $A$ \\
\hline-0.046088124 & 0.039270892 & 0.704009365 & A \\
\hline-0.046109631 & 0.039085469 & 0.704014576 & C \\
\hline-0.046128612 & 0.039257299 & 0.704099176 & A \\
\hline-0.046138684 & 0.039068228 & 0.703908854 & A \\
\hline-0.046048495 & 0.039044299 & 0.703004192 & A \\
\hline
\end{tabular}

(Figure 3) (a) Real-time eye and gaze tracking (b) Coordinate data and symbolic ROI sequence

\section{Experiment}

\subsection{Participants}

Six participants (4 male, 2 female) from South Korea were recruited. Although the participants were conveniently sampled, we made sure of proportionate sampling of gender, age, and other demographic factors. They received course credits for participating. Participants ranged in age from 24 to 56 years $(\mathrm{M}=35.00$ years, $\mathrm{SD}=14.79$ years $)$. All held a valid driving license issued by the government. Average years of driving experience of subjects is 9 years.

\begin{tabular}{|c|c|c|c|}
\hline No. & Age & Gender & Driving Experience \\
\hline 1 & 56 & M & 27 years \\
\hline 2 & 52 & F & 10 years \\
\hline 3 & 24 & M & 3 years \\
\hline 4 & 26 & F & 3 years \\
\hline 5 & 26 & M & 5 years \\
\hline 6 & 26 & M & 6 years \\
\hline
\end{tabular}

$<$ Table 1> Experiment Participants

\subsection{Procedure}

Participant was guided to an eye-tracking 
system equipped car. After all procedure of calibration that was explained previous part, participants were trained shortly to adapted eye-tracking system in order to clear eye-tracking data. Then, researcher gave instruction of the experiment to participants. Each participants should do lane change 40 times(20 left and 20 right) in natural driving and driver's eye movement data and scene camera data were recorded during each lane changes by researcher. The driving environments was $3 \mathrm{~km}$-long straight general road, participants did continuous round driving until the data collecting is over.

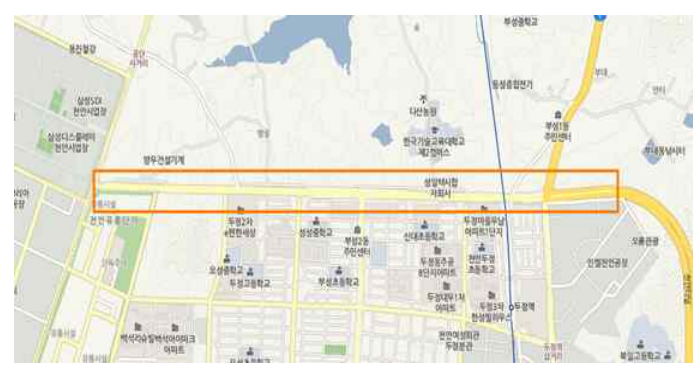

(Figure 4) Experiment environment (General road in Cheonan City in Korea)

\section{Result}

\subsection{Data Analysis}

120 left lane change and 120 right lane change symbolic ROI sentences was collected from experiment. Pate was used for transforming and checking the context free grammar Symbolic ROI sentence data. Pate is a interactive tool for parsing and transforming grammars. It can show the textual or graphical visualization of a derivation for a given grammar (restricted or unrestricted). With the textual visualization, a step-by-step derivation is displayed including the rules used at each step.

In the process of making grammar, the domain $\mathrm{C}$, we let $\mathrm{DC}=\{\mathrm{D} 1, \mathrm{D} 2, \ldots\}$ represent the set of detectors for generating the set of terminal symbols VT. For the sake of convenience and parsimonious method, the likelihood of a detected event, i.e., the likelihood of generating the terminal symbol xi corresponding to detector $\mathrm{Di}$, is given by $\mathrm{PD}(\mathrm{xi})=\mathrm{P}(\mathrm{Di})$, where $\mathrm{P}(\mathrm{Di})$ is defined on $\mathrm{a}$ case by case basis. By processing an activity sequence in domain $\mathrm{C}$, we use $\mathrm{DC}$ to generate symbolic string $\mathrm{x}=\mathrm{x} 1 \mathrm{x} 2, \ldots, \mathrm{xl}$, with length, $1=|x|$.

\subsection{Results}

We applied context-free grammars for recognizing driver's behavior pattern in the context of lane change. For the grammar generation, transforming coordinate eye tracking data of symbolic sequence was conducted. Using generating symbol, grammar structure was made. Then it was transformed through the tool for context free grammar checker. From these process, we found left and right lane change behavior context-free grammar respectively.

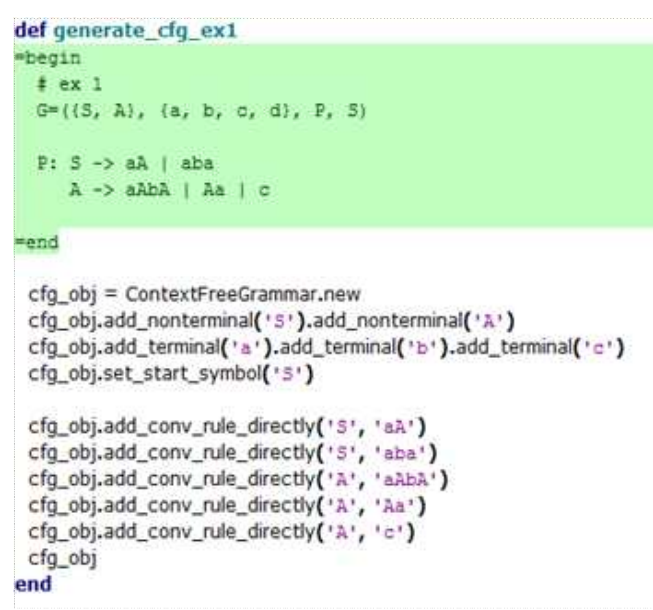




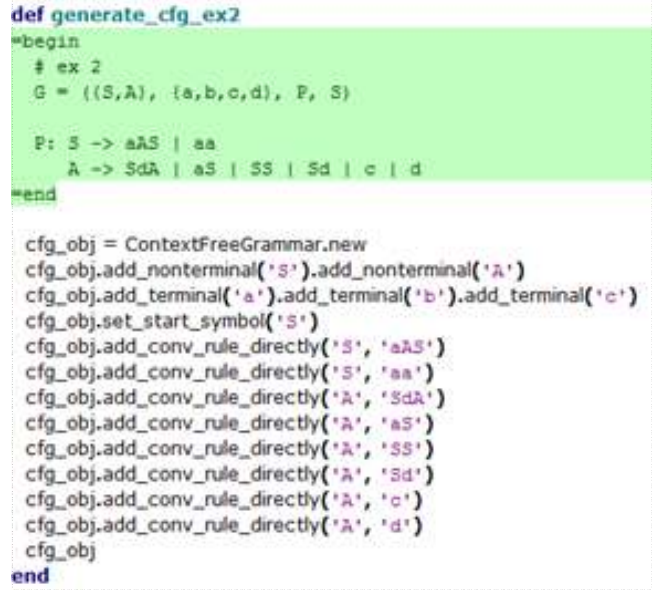

(Figure 5) (a) Left lane change CFG, (b) Right lane change CFG

\section{Discussion}

In this paper, we focused on making context free grammar of driver's lane change behavior based on ROI symbolic sequence. In recognition research of short-term events, researchers usually using statistical pattern recognition technique. Yet it was difficult to compared to the huge dimensionality of its feature space activities with very little training data. In addition, semantically equivalent activities may often have feature values that are quite far apart. In this regard, a syntactic model of the event structure based on stochastic context-free grammar was applied because of its intuition. The behavior sequence from the generated grammar is composed of symbols like A, B, C, D. It is easier to recognize and understand, and more intuitive for us. It can be applied to various area for example novice driver training, traffic psychology and so on.

In addition, it can be improved through the parsing. It is possible to compute the syntactical likelihood of a sequence of events $\mathrm{P}(\mathrm{x})$ using parser. Such likelihood offers a measure of how much semantic merit a sequence has. The parser correct substitution and insertion errors and handle concurrent tracks from separate objects using insertion error correction. Heuristically, it is also possible to understand what is essential behavior components awe can make classifier of safety driving behavior; it can be one of the important future work.

\section{References}

[1] Traffic Agency, "Analysis of Traffic Accident in 201 2," Government Research Center of Traffic Safety and Control, pp. 37-38, 2012.

[2] Doshi, Anup, Brendan Morris, and Moham M. Trived i. "On-road prediction of driver's intent with multim odal sensory cues." IEEE Pervasive Computing 10.3, 2011

[3] R. R. Mourant and R. J. Donahue, "Mirror sampling characteristics of drivers," Society of Automotive E ngineers, no. 740964, 1974.

[4] L. Tijerina, W. R. Garrott, D. Stoltzfus, and E. Parme $r$, "Eye glance behavior of van and passenger car drivers during lane change decision phase," Transp ortation Research Record, vol. 1937, pp. 37 - 3, 2005.

[5] Morris, Brendan, Anup Doshi, and Mohan Trivedi. "Lane change intent prediction for driver assistance: On-road design and evaluation." Intelligent Vehicle s Symposium (IV), 2011 IEEE. IEEE, 2011.

[6] S. E. Lee, C. B. Olsen, and W. W. Wierwille, "A comp rehensive examination of naturalistic lane changes," Report DOT HS 809702, NHTSA, U.S. Department of Transportation, March 2004.

[7] N. Oliver and A. P. Pentland, "Graphical models for driver behavior recognition in a smartcar," IEEE Pr oceedings of Symposium on Intelligent Vehicles, 200 0 .

[8] H. Berndt, J. Emmert, and K. Dietmayer, "Continuou $\mathrm{s}$ driver intention recognition with hidden markov models," in Proc. IEEE Conf. Intell. Transport. Sys 
t., Oct. 2008.

[9] N. Kuge, T. Yamamura, O. Shimoyama, and A. Liu, "A driver behavior recognition method based on a driver model framework," Proceedings of the Societ $\mathrm{y}$ of Automotive Engineers World Congress, 2000.

[10] J. C. McCall, D. Wipf, M. M. Trivedi, and B. Rao, "Lane change intent analysis using robust operators and sparse bayesian learning," IEEE Trans. Intell. Transp. Syst., vol. 8, no. 3, pp. 431 - 440, Sep. 2007.

[11] A. Doshi and M. M. Trivedi, "On the roles of eye gaze and head pose in predicting driver's intent to change lanes," IEEE Trans. Intell. Transp. Syst., vo 1. 10 , no. 3 , pp. $453-462$, Sep. 2009

[12] S. Y. Cheng and M. M. Trivedi, "Turn-intent analy sis using body pose for intelligent driver assistanc e," IEEE Pervasive Computing, vol. 5, no. 4, pp. 28 -

7 , pecial Issue on Intelligent Transportation System s, 2006 .

[13] Joo, Seong-Wook, and Rama Chellappa. "Recognitio n of multi-object events using attribute grammars." Image Processing, IEEE International Conference o n. IEEE, 2006.

[14] Vogler, Christian, and Dimitris Metaxas. "A frame work for recognizing the simultaneous aspects of american sign language." Computer Vision and Ima ge Understanding 81.32001.

[15] Bremond, F., and Medioni, G. 1998. Scenario recogni tion in airborne video imagery. In DARPA Image Understanding Workshop 1998.

[16] Ivanov, Yuri A., and Aaron F. Bobick. "Recognition of visual activities and interactions by stochastic pa rsing." Pattern Analysis and Machine Intelligence, IEEE Transactions on 22.8, 2000.

[17] Moore, D.; Essa, I.; and Hayes, M. 1999b. Exploiting human actions and object context for recognition tas ks. In ICCV'99, 80 - 86, 1999
[18] Taylor, R. G., "Models of Computation and Formal Languages", Oxford University Press., 1998.

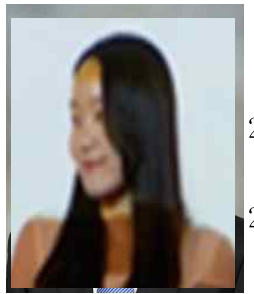

$$
\text { 조 두 리 }
$$

2011년: 아주대학교 전자공학과/심 리학과 학사

2014년: 성균관대학교 인터랙션 사이언스 학과 석사

2014년 현 재: 인터랙션 사이언스 연구소 연구원 관심분야: Driver interface, $\mathrm{HCI}, \mathrm{UX}, \mathrm{SNS}$ 등

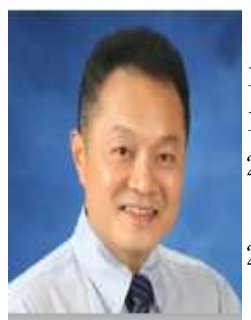

\section{신 동 희}

1997년 : 성균관대학교 학사 1999년: 남일리노이대 텔리컴 석사 2001년 : 시라큐스대학교 정보과학 석사

2004년: 시라큐스대학교 정보과학 박사

2002년 2004년: Syracuse University 전임강사

2004년 2009년: Penn State University 조교수

2009년 현 재: 성균관대학교 인터랙션 사이언스 교 수

관심분야: 인간-컴퓨터 상호작용, 인터랙션, 디지털 콘텐츠, 등 